\title{
Alkaline phosphatase for immunocytochemical labelling: problems with endogenous enzyme activity
}

\author{
ANDREW S BULMAN, EADIE HEYDERMAN \\ From the Department of Histopathology, St Thomas's Hospital Medical School, London SE1 7EH
}

SUMMARY Alkaline phosphatase may be used as a label for immunocytochemistry and can be demonstrated in tissue sections using the single step naphthol phosphate method. Endogenous enzyme activity may not be destroyed by fixation in formalin, formol alcohol, Carnoy's or Baker's solutions and should be inhibited before results are assessed. Either Bouin's solution or periodic acid followed by potassium borohydride are satisfactory inhibitors and do not adversely affect immunocytochemical results.

Immunocytochemical methods using enzyme linked antibodies are rapidly becoming routine in histopathological laboratories. ${ }^{1}$ Horseradish peroxidase is the most widely used enzyme label and of the substrates available, 3,3'-diaminobenzidine (DAB) gives the best results. Alkaline phosphatase can be used either as an alternative enzyme or in addition to DAB in double labelling experiments.

Grosser and Hasler showed in $1912^{2}$ that animal tissues hydrolysed phosphate esters and, after the introduction of the metal-salt method by Gomori in $1939,^{3}$ alkaline phosphatase was demonstrated in a wide range of tissues. Gomori noted that formalin fixation did not completely abolish enzyme activity. The use of aromatic substrates, first described by Menten $^{4}$ in 1944 , was developed by Burstone ${ }^{5}$ into a single step method in which a substituted naphthol is hydrolysed, the reaction product being visualised by simultaneous coupling with an azo dye.

\section{Material and methods}

Single step naphthol phosphate method: A stock solution $(0 \cdot 1 \% \mathrm{wt} / \mathrm{vol})$ of naphthol ASBI disodium salt (Sigma N2250) in veronal acetate buffer pH 9.1 is made and kept at $4^{\circ} \mathrm{C}$. Just before use, fast blue RR azo dye (Lamb C137155) is added to the stock solution to give a concentration of $1 \mathrm{mg} / \mathrm{ml}$; the solution is filtered on to sections which are incubated for 10 minutes at room temperature. After rinsing in tap water the sections are counterstained with $0.05 \%$ neutral red, air-dried in an oven and dry

Accepted for publication 8 May 1981 mounted in a synthetic resin mountant. Fast red azo dye (Lamb C137125) gives equally good results, but contrasts poorly with the reaction product of DAB when used for double labelling.

Cryostat sections $(6 \mu \mathrm{m})$ of rat kidney, human placenta and breast all contain alkaline phosphatase and were used as positive controls. To study the effect of fixation, pieces of fresh tissue $\left(1 \mathrm{~cm}^{2} \times 3 \mathrm{~mm}\right.$ thick) were exposed to either $10 \%$ unbuffered formalin, Zenker's, Helly's, Heidenhain's or Baker's solutions overnight, Carnoy's fluid for two hours or Bouin's overnight followed by $70 \%$ ethanol, all at room temperature. The fixed tissues were then embedded in paraffin wax and sections $(3 \mu \mathrm{m})$ cut and stained to show alkaline phosphatase.

Endogenous enzyme activity was investigated in surgical specimens routinely fixed in unbuffered $10 \%$ formalin and embedded in paraffin wax. These specimens included benign and malignant breast tissue, carcinoma of the colon, benign hyperplastic prostate, hepatoma, normal tonsil, normal pancreas, medullary carcinoma of the thyroid, dysgerminoma of the ovary, first trimester placenta, a secondary gestational choriocarcinoma, and an acutely inflamed appendix.

Methods described for blocking endogenous peroxidase were assessed for their effect on endogenous alkaline phosphatase in cryostat sections $(6 \mu \mathrm{m})$ of rat kidney, human placenta and breast, and on paraffin sections $(3 \mu \mathrm{m})$ of the same tissues fixed in either $10 \%$ unbuffered formalin overnight or Carnoy's fluid for two hours. These methods included $0.5 \%$ hydrogen peroxide in methanol ${ }^{6}$ $0.074 \%$ hydrochloric acid in ethanol, ${ }^{7}$ each applied 
for $10 \mathrm{~min}$ and a sequence of hydrogen peroxide $6 \%$, periodic acid $2.28 \%$, each for $5 \mathrm{~min}$, followed by potassium borohydride $0.02 \%$ for 2 min. ${ }^{8}$ Bouin's fixative solution applied to sections for $5 \mathrm{~min}$ was also tried.

The indirect immunocytochemical method used was the same as that already described in detail using peroxidase conjugate, ${ }^{8}$ except that the incubation times of first antibody and conjugate were increased to one hour each. The specific antibodies of the first layer had been raised in rabbits. The antibody for the second layer had been raised against rabbit immunoglobulin in sheep, and was conjugated to alkaline phosphatase (Sigma P4502) using 1\% glutaraldehyde, as described by Avrameas. ${ }^{9}$ Commercial alkaline phosphatase-immunoglobulin conjugates were also used. To show that the alkaline phosphatase method produced a similar pattern of staining to that obtained using peroxidase and that the use of alkaline phosphate inhibition did not adversely affect immunocytochemical results, a variety of antigens were demonstrated in tissue sections. These included pregnancy specific glycoprotein $\left(\mathbf{S P}_{1}\right)$ in first trimester placenta, human placental lactogen (HPL) in term placenta, calcitonin in medullary carcinoma of thyroid, carcinoembryonic antigen (CEA) in carcinoma of the colon and $\beta$-human chorionic gonadotrophin ( $\beta$-HCG) in metastatic gestational choriocarcinoma. The negative control in each case was absorption of the antiserum with the appropriate antigen.

To confirm that more than one antigen can be demonstrated in the same section, ${ }^{10}$ double labelling experiments were performed using first antibodies raised to the antigens in different species, with the appropriate second antibody. The final reaction product of the peroxidase system was developed before embarking on the second cycle using the alkaline phosphatase system.

\section{Results}

The positive control sections of rat kidney, human placenta and breast all demonstrated very intense enzyme activity which gave rise to some crystallisation of the azo dye. This was not a problem when the enzyme was present in smaller quantities.

Enzyme activity in all three control tissues was hardly affected by Carnoy's fixative, but was reduced in the kidney and placenta by formalin fixation, and completely abolished by Bouin's fluid. The absence of enzyme activity in breast fixed in formalin may have been due to the somewhat weaker activity in the original material. Fixation of fresh rat kidney in Zenker's, Helly's or Heidenhain's solution completely abolished alkaline phosphatase activity, but fixation in formol alcohol and Baker's solution did not.

Although most routinely processed surgical material showed no endogenous alkaline phosphataseactivity, some was detected in both the lymph node and the pancreas. The use of these sections for immunocytochemistry could have led to equivocal results. Endogenous enzyme activity was hardly affected by hydrogen peroxide in methanol or hydrochloric acid in ethanol. The hydrogen peroxide, periodic acid, borohydride sequence abolished all enzyme activity in fixed tissues, and was equally effective in frozen tissue if the hydrogen peroxide was omitted to avoid lifting of the sections. The use of Bouin's fixative applied to sections for $5 \mathrm{~min}$ also abolished all enzyme activity.

Using an alkaline phosphatase conjugated second antibody HPL was demonstrated in the wax sections of term placenta previously shown to contain endogenous alkaline phosphatase activity. The pattern of localisation of HPL in the syncytiotrophoblast was indistinguishable from endogenous enzyme activity, but the negative result obtained when the first antibody was absorbed with HPL showed that this localisation was due only to anti-HPL, and that endogenous enzyme activity had been inhibited. HPL was also shown in resin sections of the firs trimester placenta. ${ }^{12}$

Using wax sections only, $\mathbf{S P}_{1}$ was localised in firs trimester placenta, calcitonin in medullary carcinom of thyroid, CEA in carcinoma of the colon and $\beta$-HCG in metastatic gestational choriocarcinoma. Using the double labelling technique human growth hormone and prolactin were shown in the pituitary, and, using antisera raised in two different species to human placental lactogen, segregation of staining in a malignant trophoblastic tumour due to recognition of two different antigenic determinants was seen. ${ }^{12}$

\section{Conclusion}

Alkaline phosphatase is a convenient enzyme label for immunocytochemistry and the reagents for its use are readily available in any histopathology laboratory. As with DAB, care should be taken in handling the reagents. Endogenous alkaline phosphatase activity is a problem, especially in fresh material. Previous publications ${ }^{10} 13$ involving fixed material have not mentioned this activity but clearly it should be inhibited before immunocytochemical results are interpreted. Treatment in Bouin's solution for 5 min effects satisfactory inhibition and causes no apparent loss of antigenicity. Since the hydrogen peroxide-periodic acid method inhibits both peroxidase and phosphatase activity, this is the preferred method for immunocytochemistry in 
laboratories where both enzymes are in regular use. We wish to thank $\mathrm{Mr} \mathrm{J}$ Reynolds for advice, Ms G Powell for technical assistance and Mrs S King for secretarial help.

\section{References}

${ }^{1}$ De Lellis RA, Sternberger LA, Mann RB, Banks PM, Nakane PK. Immunoperoxidase technics in diagnostic pathology. Am J Clin Pathol 1979;71:483-8.

Grosser P, Hasler J. Über das Vorkommen einer Glycerophosphotase in tierischen Organen. Biochem Zeit 1912; 39:1-5.

${ }^{3}$ Gomori G. Microtechnical demonstration of phosphatase in tissue sections. Proc Soc Exp Biol Med 1939;42:23-6.

4 Menten MK, Junge J, Green MA. A coupling histochemical azo-dye test for alkaline phosphatase in the kidney. J Biol Chem 1944;153:471-517.

${ }^{5}$ Burstone MS. Enzyme histochemistry. London: Academic Press, 1972.

${ }^{6}$ Streefkerk JG. Inhibition of erythrocyte pseudoperoxidase activity by treatment with hydrogen peroxide following methanol. J Histochem Cytochem 1972;20:829-31.

7 Weir EE, Pretlow TG, Pitts A, Williams EE. Destruction of endogenous peroxidase activity in order to locate cellular antigens by peroxidase labelled antibodies. J Histochem Cytochem 1974;22:51-4.

${ }^{8}$ Heyderman E. Immunoperoxidase technique in histopathology: Applications, methods, and controls. $J$ Clin Pathol 1979;32:971-8.

${ }^{9}$ Avrameas S. Coupling of enzymes to proteins with glutaraldehyde. Immunochemistry 1969;6:43-52.

${ }^{10}$ Mason DY, Sammons R. Alkaline phosphatase and peroxidase for double immunoenzymatic labelling of cellular constituents. J Clin Pathol 1978;31:454-60.

${ }^{11}$ Heyderman E, Monaghan P. Immunoperoxidase reactions in resin-embedded sections. Invest Cell Pathol 1979;2: 119-22.

12 Heyderman E, Bulman AS, Gibbons A. Immunoperoxidase method in pathology. J Clin Pathol 1980;12: 1219-20.

${ }^{13}$ Druguel M, Pepys MB. Enumeration of lymphocyte populations in whole peripheral blood with alkaline phosphatase labelled reagents. Clin Exp Immunol 1977; 29:162-7.

Requests for reprints to: Dr E Heyderman, Department of Histopathology, St Thomas's Hospital Medical School, London SE1 7EH, England. 